\title{
EVIDENCIAÇÃO DO CAPITAL \\ INTELECTUAL NOS RELATÓRIOS DE SUSTENTABILIDADE EM EMPRESAS DO SETOR BANCÁRIO
}

\section{EVIDENTIATION OF INTELLECTUAL CAPITAL IN SUSTAINABILITY REPORTS IN COMPANIES OF THE BANKING SECTOR}

\section{DOI: http://dx.doi.org/10.21714/raunp.v10i1.1717}

Leonardo Fabris Lugoboni

Doutor e Mestre em Administração. Professor na FECAP. E-mail: leo_fabris@hotmail.com

\section{Fernanda Sousa de Andrade}

Especialista em Controladoria. FECAP. E-mail: fernandasousa98@gmail.com

\section{Marcus Vinicius Moreira Zittei}

Doutor em Ciências Contábeis e Administração. Professor na FECAP. E-mail: marcuszittei@zittei.com.br

\section{Rina Xavier Pereira}

Doutoranda em Administração. Mestre em Ciências Contábeis. Professora na FECAP E-mail: rinaxp@gmail.com

Envio em: Setembro de 2017

Aceite em: Fevereiro de 2018

\section{RESUMO}

Este estudo buscou identificar o nível de evidenciação dos elementos do Capital Intelectual nos relatórios de Sustentabilidade no formato GRI dos bancos citados na Bolsa de Valores de São Paulo (B3). Utilizou-se o método descritivo, por meio de pesquisa documental em que foram utilizadas técnicas de analise de conteúdo com base em uma amostra de 6 instituições financeiras. Todas as empresas evidenciaram valorização dos funcionários; educação e treinamentos; marcas e patentes; cultura corporativa; clientes e colaborações comerciais/relacionamento com stakeholders. Com relação ao volume de evidenciações, os itens mais evidenciados foram "Colaborações comerciais/ Relacionamento com stakeholders" e "Clientes" no capital relacional, "Sistemas de informações" no capital estrutural e "Valorização do funcionário" e "Educação/ Treinamento" no capital humano.

Palavras-chave: Capital intelectual. Sustentabilidade. Relatório GRI.

\section{ABSTRACT}

This study sought to identify the level of disclosure of the elements of Intellectual Capital in the Sustainability reports in the GRI format of the banks listed on the São Paulo Stock Exchange (B3). The descriptive method was used, through documentary research in which content analysis techniques were used based on a sample of 6 financial institutions. All the companies showed appreciation of the employees; education and training; brands and patents; corporative culture; clients and business collaborations / relationships with stakeholders. With regard to the volume of evidences, the most evidenced items were "Business Collaborations / Relationship with stakeholders" and "Clients" in relational capital, "Information systems" in structural capital and "Employee valorization" and "Education / Training" in capital human.

Key-words: Intellectual capital. Sustainability. GRI. 


\section{INTRODUÇÃO}

No cenário atual, a competitividade tem impulsionado as empresas cada vez mais, a buscarem um diferencial para se manterem no mercado. Como consequência da globalização recursos materiais, estruturais e tecnológicos são facilmente reproduzidos pela concorrência e já não representam um dos principais recursos das organizações, mas sim o conhecimento.

O conhecimento é um ativo intangível resultado da capacidade de raciocínio do ser humano, que diferente dos ativos tangíveis não se desgasta, não se deprecia e não perde seu valor quando utilizada, pelo contrário, é uma fonte inesgotável, que sendo aprimorada e bem gerenciada, pode valorizar qualquer ativo da organização, resultando em vantagens e geração de valor para mesma. (MOREIRA; VIOLIN; SILVA, 2014, p.300).

Um dos principais objetivos das organizações é otimizar esta geração de valor, que serve tanto como instrumento de avaliação das empresas, como ferramenta na tomada de decisões. Para tal otimização não basta apenas o enfoque no desempenho financeiro, mas também da performance nas vertentes social e ambiental (REZENDE; AVILA; MAIA, 2012, p.52). Segundo o Conselho Empresarial Brasileiro para o Desenvolvimento Sustentável (CEBDS) (2014, p.12) "o ativo intangível ou capital intelectual representa em média $80 \%$ do valor de mercado de uma empresa de capital aberto", mostrando a importância de sua evidenciação nas demonstrações e relatórios ao mercado.

Barakat et al. (2016) afirma que de forma geral os investidores procuram por empresas socialmente responsáveis, sustentáveis e rentáveis para aplicar seus recursos, já que estas geram valor para seus acionistas no longo prazo, por estarem mais preparadas para enfrentar riscos econômicos, sociais e ambientais.

Entre as ações que demonstram iniciativas das instituições em se adequar a essas premissas sociais encontra-se a publicação de relatórios de sustentabilidade, que é um documento onde se demonstra a sociedade, iniciativas socialmente responsáveis adotadas pelas empresas no intuito de reduzirem os impactos sociais, ambientais e econômicos gerados por suas operações, demonstrados também por indicadores de sustentabilidade (SOUZA; LOPES, 2010).

Dentre os relatórios que servem de modelo para a publicação no Brasil se destacam o do Instituto Ethos (2011) e o da Global Reporting Initiative (GRI), que apresentou um crescimento significativo na última década em número de empresas que utilizam essa metodologia (CORREA et al. 2012).

O artigo objetiva evidenciar o Capital Intelectual nos Relatórios de Sustentabilidade nas empresas do setor bancário de forma a responder o seguinte questionamento: Como as instituições financeiras estão demonstrando em seus relatórios de sustentabilidade a preocupação com o Capital Intelectual?

Esta pesquisa se justifica, pois, ainda não há muitos estudos que demonstrem a relação entre a sustentabilidade e capital intelectual e ainda, tem o intuito de contribuir para a literatura acerca da importância do capital intelectual como instrumento importante na geração de valor das organizações. Segundo Zanol et al., (2015) é importante ressaltar que as empresas para se manterem no mercado, altamente competitivo, estão constantemente em busca de um diferencial, além de medidas sustentáveis como a preocupação ambiental e social, de investimento em seu pessoal e também na sociedade em que está inserida, o capital intelectual passou a ser um investimento fundamental.

\section{REFERENCIAL TEÓRICO}

\subsection{CAPITAL INTELECTUAL: CONCEITOS E DEFINIÇÕES}

Atualmente as organizações estão cada vez mais, inseridas em um ambiente economicamente competitivo, e diante deste cenário, o capital intelectual, assim como a valorização do conhecimento como recurso econômico, são diferenciais para um melhor resultado lucrativo e recurso decisivo para as empresas se manterem competitivas (ANTUNES; 2005, p.9; MARQUES; GOMES, 2011, p. 72).

Segundo Stewart (1998) um dos principais estudiosos do tema, o capital intelectual é a soma do conhecimento de todos em uma empresa, o que lhe proporciona vantagem competitiva. Ao contrário dos ativos como: propriedade, fabricas, equipamentos e dinheiro, o capital intelectual é intangível e é constituído pelo conhecimento, informação, propriedade intelectual, e experiência, que podem ser utilizados na geração de riqueza.

Já Edvinsson e Malone (1998), utilizam-se de uma metáfora ao conceituar o capital intelectual, através 
da comparação de uma empresa com uma arvore, sendo a parte visível, correspondente aos troncos, galhos e folhas, que seriam os recursos descritos nos organogramas, demonstrações contábeis e outros documentos. E abaixo da superfície estariam as raízes, representando o capital intelectual, que através de fatores dinâmicos e ocultos embasam e amparam a parte visível.

O capital intelectual é divido em três categorias: capital humano, estrutural e relacional ou de clientes.

\subsubsection{CAPITAL HUMANO}

De acordo com Edvinsson e Malone (1998, p.31) o capital humano pode ser conceituado como toda a capacidade, conhecimento, habilidade e experiência individuais dos funcionários adicionados aos valores, cultura e filosofia da empresa. Os autores ainda apontam a criatividade e a inovação organizacionais como características do capital humano, demonstrando a frequência com que novas ideias estão sendo geradas e implementadas na organização, bem como a porcentagem de êxito destas.

Utilizando-se da metáfora de Edvinsson e Malone, Stewart (1998, p.77) evidencia a importância do capital humano ao mencionar que, se a organização é uma arvore, os funcionários são a seiva que a faz crescer. Nas palavras do mesmo autor o dinheiro pode até ter poder, porém não pensa, as maquinas operam, porém não inventam, já quanto ao capital humano, este "é a fonte de inovação e renovação dentro da organização" (STEWART, 1998, p.68).

Stewart $(1998$, p.77) enfatiza que a principal característica do capital humano é a inovação, com foco na criação de novos produtos e serviços, ou em melhorias de processos nos negócios, que objetivam geração de vantagem competitiva e de valor. Sendo assim, não é considerado capital humano, no contexto de capital intelectual, o trabalho rotineiro, feito de forma manual que exija pouca habilidade, e cuja função poderia ser automatizada. O capital humano é formado e empregado quando os funcionários dedicam o seu tempo e talento em atividades que gerem inovação.

É através das pessoas que são produzidos todos os demais ativos da organização, sendo assim, é necessário investimento em treinamentos, recicla- gens e politicas motivacionais como medidas para valorizar e estimular o trabalho e também para o aperfeiçoamento e a aquisição de novas habilidades. O Capital humano necessita estar em conjunto com o Capital Estrutural, sendo preciso uma boa estrutura em termos de sistemas de informação, processos, para que o capital humano tenha condições de atuar no desenvolvimento de suas atividades (MARQUES, GOMES, 2011).

\subsubsection{CAPITAL ESTRUTURAL}

O capital estrutural trata-se da infraestrutura organizacional existente na empresa que serve de apoio ao capital humano, envolvendo a capacidade organizacional, constituída pelo planejamento administrativo, sistemas de controle; bem como a qualidade e o alcance destes processos, redes funcionais, politicas, pela imagem da empresa, e também pela cultura da organização (PACHECO, 2005; CARVALHO; SOUZA, 1999, p. 75).

De acordo com Marque e Gomes (2011, p.76), existe uma troca de benefícios entre o capital humano e o estrutural, já que enquanto o capital estrutural dá condições necessárias para o desenvolvimento do capital humano, este por sua vez edifica e consolida o capital estrutural.

Edvinsson e Malone (1998, p.32), dividem para melhor compreensão, o capital estrutural em 3 categorias: organizacional, de inovação e de processos conforme exposto abaixo:

Capital Organizacional: engloba tudo aquilo que fornece suporte para o capital humano, abrangendo o investimento da empresa em sistemas de informação, em instrumentos e filosofia operacional, para melhor agilidade no fluxo de conhecimento pela organização e também para as áreas externas.

Capital de Inovação: é tudo aquilo que gera capacidade de inovação e renovação dentro da empresa sob a forma de direitos comerciais amparados por lei, compreende a propriedade intelectual da empresa, como marcas, patentes e direitos autorias. Capital de processos é constituído por conjunto de técnicas, processo e programas direcionados aos colaboradores que propiciam o aumento da eficiência da produção ou prestação de serviço, como exemplo ISO 9000, manuais de procedimentos e normas e procedimentos internos. (MARQUES; GOMES, 2011, p.77). 


\subsubsection{CAPITAL RELACIONAL OU DE CLIENTE}

Segundo Carvalho e Souza (1999, p. 75) o capital relacional ou de cliente diz respeito ao valor dado aos relacionamentos de uma empresa com as pessoas com as quais faz negócio, ou seja, seus clientes e fornecedores, com quem são criadas parcerias estratégicas.

De acordo com Stewart (1998, p. 128) dentre as três categorias de ativos intelectuais - capitais humano, estrutural e de cliente - os clientes são os mais valiosos, uma vez que são os que pagam as contas e possibilitam que a organização se mantenha ativa em suas atividades.

As relações entre organização e seus clientes e fornecedores agregam valor, através da fidelidade dos clientes, que gera vendas costumeiras e reduz os custos da busca por novos; através do cultivo de bons fornecedores aumentando a qualidade, em termos de produtos e serviços (acertando, já na primeira vez), o que também reforça a velocidade necessária para atingir as metas de comercialização (PACHECO, 2005, p. 54).

\subsection{SUSTENTABILIDADE E RELATÓRIO GRI}

Num conceito geral a sustentabilidade se refere a capacidade de atender as necessidades da geração atual sem interferir com a capacidade de suprir as necessidades das gerações futuras. Elkington (2012, p. 20) corrobora esta ideia definindo sustentabilidade como o "princípio de assegurar que nossas ações de hoje não limitarão a gama de opções econômicas, sociais e ambientais disponíveis para as gerações futuras".

Um dos modelos mais abordados de operacionalização de sustentabilidade ou desenvolvimento sustentável é o Triple Botton Line (TBL), conhecido como Tripé da Sustentabilidade. (ELKINGTON, 2012). Tal expressão tornou-se consagrada e também ficou conhecida como os "Três Ps" (people, planet and profit) ou, em português, "PPL" (pessoas, planeta e lucro), segundo esse conceito, uma organização sustentável é aquele que deve ser financeiramente viável, socialmente justa e ambientalmente responsável (INSTITUTO FILANTROPIA, 2008).

O Triple Botton Line (TBL) é composto pela integração de três frentes: econômica, social e ambiental; Social: Contempla o capital humano, a comunidade, a sociedade de forma geral, definindo a necessidade de salários justos e adequados à legislação trabalhista, como também o bem-estar dos funcionários; Ambiental: Refere-se ao capital natural de um empreendimento ou sociedade, indicando que é preciso amenizar o impacto ambiental negativo e compensar o que não é possível amenizar; e Econômica : Está relacionada a temas ligados à produção, distribuição e consumo de bens e serviços, devendo levar em conta outros aspectos que envolvem o setor em que a organização atua (ELKINGTON, 2012).

Há uma crescente valorização por parte da sociedade e Steakeholders, de empresas que aderem aos princípios de sustentabilidade, por evidenciar uma preocupação da organização com o futuro e também com relação a transparência de suas informações. Nesse sentido, as empresas têm buscado cada vez mais aderirem a divulgação de relatórios de sustentabilidade, visando uma maior transparência de suas informações e ações empresariais e também no que se refere a gestão sustentável das questões econômicas, sociais e ambientais (KNEIPP et al, 2013).

Os Relatórios de Sustentabilidade ou Relatório Social se destina à publicação do desempenho de uma organização, considerando um equilíbrio entre os aspectos ambientais, econômicos e sociais (GRI, 2013). Sua elaboração e divulgação é opcional e voluntária, e muitos são os padrões existentes para orientar a construção destes relatórios. (KNEIPP et al., 2013).

A Global Reporting Initiative - GRI é uma instituição não governamental, sem fins lucrativos, que trabalha por uma economia global sustentável através da divulgação de diretrizes para elaboração dos relatórios de sustentabilidade (GRI, 2013). O modelo de relatório GRI representa um dos escopos mais abrangentes, utilizado mundialmente para fins de elaboração de relatórios de sustentabilidade pelas empresas (KNEIPP et al., 2013).

\subsection{ESTUDOS CORRELATOS}

Foram identificados dois estudos correlatos ao tema abordado. Sousa, et al., (2008), tinham como objetivo analisar a evidenciação do CI das 15 maiores companhias de Energia Elétrica listadas na Bolsa de Valores de São Paulo (B3) através da analise dos 
Relatórios da Administração, mostrando quais empresas mais o evidenciam, com que frequência, bem como fazer um comparativo entre as companhias da amostra nos anos de 2006 e 2007. E concluíram que os resultados foram positivos e demonstram uma tendência de crescimento, já que, no ano de 2007, houve uma evolução, ainda que pequena, em relação a algumas empresas, sobre 2006 .

Os itens mais evidenciados na pesquisa de Sousa, et al., (2008) foram Clientes, Filosofia Gerencial, Educação e Sistemas de Informação, já os menos evidenciados foram Patente, Direitos autorais, Marcas registradas e Acordo de franchising. E conclui-se que a categoria mais evidenciada também foi a de Capital externo e/ou Capital de clientes.

Zanol, et al., (2015) objetivou verificar a evidenciação do Capital Intelectual nos relatórios de sustentabilidade de um grupo de empresas de energia elétrica listadas na B3. E verificou-se que mesmo as empresas não utilizando os termos Capital Intelectual, bem como seus componentes: Capital Humano, Capital Estrutural e Capital do Cliente, por falta de normatização referente a divulgação deste tema, foi possível identificar evidenciação dos elementos do Capital Intelectual nos relatórios de sustentabilidade analisados.

\section{METODOLOGIA}

Segundo Gil (2002), a pesquisa é um procedimento que objetiva proporcionar respostas aos problemas que são levantados. O presente estudo caracteriza-se como uma pesquisa descritiva, que nas palavras do mesmo autor, tem a finalidade de descrever características de determinada população ou fenômeno, estabelecendo relações entre as variáveis.

Quanto aos procedimentos técnicos trata-se pesquisa documental através da coleta dos dados, que se refere ao uso de materiais que receberam algum ou nenhum tratamento analítico (GIL,2002, p. 46).

\subsection{COLETA DE DADOS}

Inicialmente foi utilizada uma amostra as 23 instituições bancárias mencionadas na lista da B3. Porém das empresas listadas no site da instituição, foram analisadas somente aquelas que possuíam Relatório de Sustentabilidade no modelo GRI referente ao período de 2015, o que restringiu a amostra a 6 empresas.

TABELA 1: AMOSTRA - EMPRESAS SETOR BANCÁRIO COM RELATÓRIO DE SUSTENTABILIDADE NO MODELO GRI 2015.

\begin{tabular}{|c|l|c|c|c|}
\hline & BANCO & $\begin{array}{c}\text { TIPO DE } \\
\text { MERCADO }\end{array}$ & $\begin{array}{c}\text { NUMERO DE } \\
\text { FUNCIONARIOS }\end{array}$ & $\begin{array}{c}\text { LUCRO } \\
\text { LIQUIDO }\end{array}$ \\
\hline 1 & BCO AMAZONIA S.A. & BOLSA & 4.101 & 249 Milhões \\
\hline 3 & BCO BRADESCO S.A. & NIVEL 1 & 93.000 & 17,8 Bilhões \\
4 & BCO BRASIL S.A. & Novo Mercado & 109.191 & 14,4 Bilhões \\
\hline 5 & BCO SANTANDER (BRASIL) S.A. & NIVEL 2 & 1.533 & 432 Milhões \\
6 & ITAU UNIBANCO HOLDING S.A. & NIVEL 1 & 193.863 & 6,62 Bilhoes \\
\hline
\end{tabular}

Fonte: Elaborado pelos autores.

Para identificação dos tópicos a serem examinados para identificação do CI nas informações de Sustentabilidade, partiu-se do desenvolvimento da Tabela 2, onde foi consolidado os principais aspectos de capital intelectual identificados através da leitura de 7 artigos que abordaram o tema. A coleta de dados foi realizada através da leitura dos Relatórios de Sustentabilidade das empresas da amostra. 
TABELA 2: ELEMENTOS DO CAPITAL INTELECTUAL EM ARTIGOS SOBRE O TEMA - CHECK LIST1.

\section{CAPITAL INTELECTUAL}

\section{AUTORES}

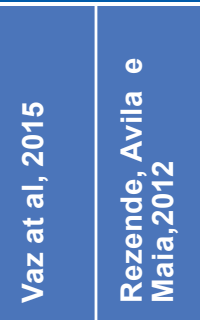

농

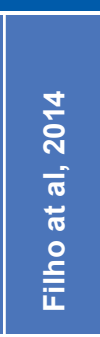

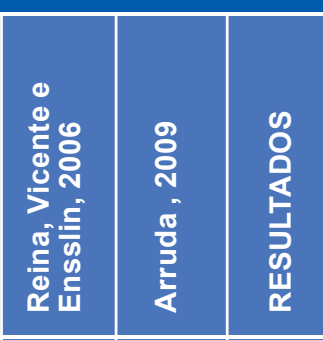

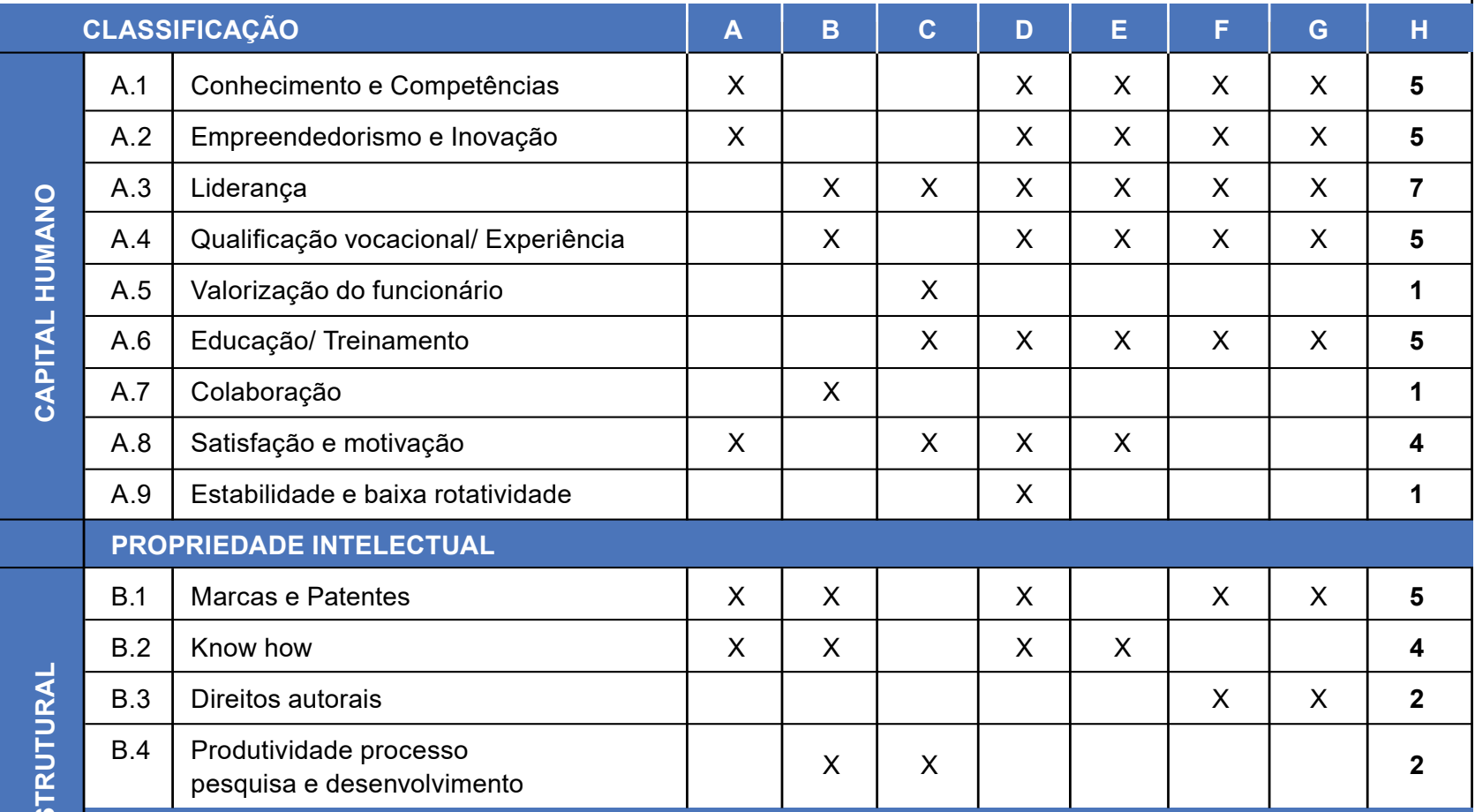

ATIVOS DE INFRAESTRUTURA

\begin{tabular}{|l|l|c|c|c|c|c|c|c|c|}
\hline B.5 & Adequação estrutural & $\mathrm{X}$ & $\mathrm{X}$ & & & & & & $\mathbf{2}$ \\
\hline B.6 & Filosofia gerencial & & & & $\mathrm{X}$ & $\mathrm{X}$ & $\mathrm{X}$ & $\mathrm{X}$ & $\mathbf{4}$ \\
\hline B.7 & Cultura corporativa & $\mathrm{X}$ & & $\mathrm{X}$ & $\mathrm{X}$ & $\mathrm{X}$ & $\mathrm{X}$ & $\mathrm{X}$ & $\mathbf{6}$ \\
\hline B.8 & Processos gerenciais & $\mathrm{X}$ & $\mathrm{X}$ & & $\mathrm{X}$ & & $\mathrm{X}$ & $\mathrm{X}$ & $\mathbf{5}$ \\
\hline B.9 & Sistemas de informações & $\mathrm{X}$ & $\mathrm{X}$ & $\mathrm{X}$ & $\mathrm{X}$ & $\mathrm{X}$ & $\mathrm{X}$ & $\mathrm{X}$ & $\mathbf{7}$ \\
\hline C.1 & Clientes & $\mathrm{X}$ & $\mathrm{X}$ & $\mathrm{X}$ & $\mathrm{X}$ & $\mathrm{X}$ & $\mathrm{X}$ & $\mathrm{X}$ & $\mathbf{7}$ \\
\hline C.2 & Marketing & & & & $\mathrm{X}$ & & & & $\mathbf{1}$ \\
\hline C.3 & Contratos favoráveis & & $\mathrm{X}$ & & $\mathrm{X}$ & $\mathrm{X}$ & $\mathrm{X}$ & $\mathrm{X}$ & $\mathbf{5}$ \\
\hline C.4 & Colaborações comerciais/ & $\mathrm{X}$ & $\mathrm{X}$ & $\mathrm{X}$ & $\mathrm{X}$ & $\mathrm{X}$ & $\mathrm{X}$ & $\mathrm{X}$ & $\mathbf{7}$ \\
\hline C.5 & Acordos / Alianças & $\mathrm{X}$ & $\mathrm{X}$ & & & & & & $\mathbf{2}$ \\
\hline C.6 & Canais de distribuição & & & & $\mathrm{X}$ & & $\mathrm{X}$ & $\mathrm{X}$ & $\mathbf{3}$ \\
\hline C.7 & Canais de atendimento/ Pós vendas & & & $\mathrm{X}$ & $\mathrm{X}$ & & & & $\mathbf{2}$ \\
\hline
\end{tabular}

Fonte: Elaborado pelos autores. 


\subsection{ANÁLISE DE DADOS}

A análise de dados foi segregada em duas tabelas, na Tabela 3 foi demonstrado se o item foi evidenciado, para isso ao identificar o item no relatório, atribuiu-se o código 1; e quando não havia menção do item no relatório atribuiu-se o código 0 .

Após as atribuições dos códigos ( 0 e 1$)$ na Tabela 3 , foi feito um somatório, no eixo vertical, dos elementos presentes na divulgação dos relatórios das empresas, demostrando qual a quantidade de elementos do capital intelectual mencionados por empresa (no caso do Banco Bradesco, foram citados 22 dos 26 elementos de CI). Posteriormente foi feito um somatório no eixo horizontal, para verificar quais itens do CI foram citados por em empresa (itens como valorização dos funcionários, cultura corporativa e clientes foram citados pelas 6 empresas analisadas).

Simultaneamente a coleta de dados da Tabela 3, foi demonstrado na Tabela 4 o volume de citações por item, através do leitura e apontamento da quantidade de vezes que o item foi mencionado nos relatórios. Realizou-se um somatório do eixo horizontal em que foi possível identificar por exemplo que o item qualificação profissional/ experiência foi citado apenas 7 vezes enquanto o item canais de atendimento/ pós-vendas foi mencionado 16 vezes.

Posteriormente aos somatórios, foi possível analisar a frequência de divulgação em cada uma das categorias de CI (Capital Interno, Capital Externo e Capital Humano).

\section{APRESENTAÇÃO DOS RESULTADOS}

$\mathrm{Na}$ Tabela 3 verificamos que os elementos mais evidenciados em relação ao componente Capital Humano foram a Valorização do funcionário e Educação/ Treinamento, sendo abordados nas 6 empresas analisadas. Os dois itens se complementam e demonstram o entendimento das organizações da amostra da importância do desenvolvimento de seus funcionários bem como a preocupação com sua qualidade de vida, pois ambos os aspectos impactam direta ou indiretamente em resultados positivos para as empresas, que produzem profissionais capacitados a gerar novas ideias e motivados a trabalhar e contribuir com a alavancagem da organização.

Os dois itens menos citados dentro deste grupo foram Colaboração e Qualificação vocacional/ Experiência, ambos citados em apenas 2 relatórios. Acredita-se que a colaboração, apesar de ser uma das menos citadas esteja relacionada e representada de forma implícita pelos itens motivação e satisfação dos funcionários, citados em 4 das 6 empresas, que gera por partes desses, um maior empenho e desejo de colaboração. Já em relação a baixa evidenciação do item Experiência, vai em contrapartida ao item Educação e Treinamento, mostrando que ser importante as qualificações e experienciais profissionais, porém não essenciais, visto que as organizações prezam pelo desenvolvimento do funcionário através de treinamentos internos.

No componente Capital Estrutural, cultura corporativa e marcas e patentes foram os mais citados. Sendo a cultura corporativa uma ferramenta importante de alinhamento de estratégia entre organização e funcionários o que resulta em maior eficiência para a organização. Já a importância da marca e reflexo do valor da organização diante da sociedade.

Corroborando com os resultados de Sousa, et al (2008), Direitos Autorais esta entre os menos citados, sendo que na amostra desta pesquisa não foi citado nenhuma vez, junto com o item Pesquisa e Desenvolvimento que foi citado em apenas duas empresas.

No componente Capital Relacional os itens mais mencionados foram Clientes e relacionamento com Stakeholders citados por todas as empresas da amostra. Os dois elementos se complementam já que clientes compõe o item relacionamento com Stakeholders, sendo um dos mais importantes, visto que são os que mantem a organização em funcionamento (STEWART, 1998). 
TABELA 3: IDENTIFICAÇÃO ELEMENTOS DO CAPITAL INTELECTUAL NOS RELATÓRIOS DE SUSTENTABILIDADE.

\begin{tabular}{|c|c|c|c|c|c|c|c|c|c|}
\hline \multicolumn{3}{|c|}{ CAPITAL INTELECTUAL } & \multicolumn{7}{|c|}{ AUTORES } \\
\hline & & & 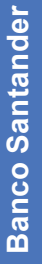 & 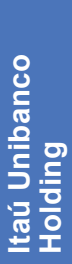 & 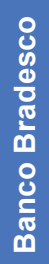 & 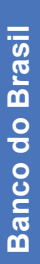 & 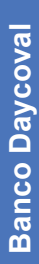 & 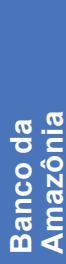 & 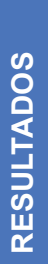 \\
\hline \multicolumn{3}{|c|}{$\begin{array}{l}\text { IDENTIFICAÇÃO DOS TÓPICOS DE CI NOS } \\
\text { RELATÓRIOS ANALISADOS }\end{array}$} & A & B & C & D & E & $\mathrm{F}$ & \\
\hline \multirow{9}{*}{$\begin{array}{l}\frac{0}{2} \\
\frac{1}{2} \\
\frac{2}{2} \\
\frac{1}{\frac{1}{2}} \\
\frac{\mathrm{E}}{\mathrm{\alpha}} \\
\frac{\mathrm{d}}{\mathrm{d}}\end{array}$} & A.1 & Conhecimento e Competências & 1 & 1 & 1 & 1 & 0 & 0 & 4 \\
\hline & A. 2 & Empreendedorismo e Inovação & 1 & 0 & 1 & 1 & 0 & 0 & 3 \\
\hline & A.3 & Liderança & 1 & 1 & 1 & 0 & 0 & 0 & 3 \\
\hline & A. 4 & Qualificação vocacional/ Experiência & 0 & 0 & 0 & 1 & 1 & 0 & 2 \\
\hline & A.5 & Valorização do funcionário & 1 & 1 & 1 & 1 & 1 & 1 & 6 \\
\hline & A. 6 & Educação/ Treinamento & 1 & 1 & 1 & 1 & 1 & 1 & 6 \\
\hline & A.7 & Colaboração & 1 & 0 & 0 & 0 & 1 & 0 & 2 \\
\hline & A. 8 & Satisfação e motivação & 1 & 1 & 1 & 1 & 0 & 0 & 4 \\
\hline & A.9 & Estabilidade e baixa rotatividade & 0 & 1 & 1 & 1 & 0 & 1 & 4 \\
\hline \multicolumn{10}{|c|}{ PROPRIEDADE INTELECTUAL } \\
\hline \multirow{4}{*}{$\frac{\frac{1}{4}}{\frac{\alpha}{2}}$} & B.1 & Marcas e Patentes & 1 & 1 & 1 & 1 & 1 & 1 & 6 \\
\hline & B. 2 & Know how & 0 & 1 & 1 & 1 & 0 & 0 & 3 \\
\hline & B.3 & Direitos autorais & 0 & 0 & 0 & 0 & 0 & 0 & 0 \\
\hline & B.4 & $\begin{array}{l}\text { Produtividade processo pesquisa e } \\
\text { desenvolvimento }\end{array}$ & 0 & 0 & 1 & 0 & 0 & 1 & 2 \\
\hline
\end{tabular}

ATIVOS DE INFRAESTRUTURA

\begin{tabular}{|c|c|c|c|c|c|c|c|c|}
\hline B.5 & Adequação estrutural & 0 & 1 & 1 & 1 & 0 & 0 & 3 \\
\hline B.6 & Filosofia gerencial & 1 & 1 & 1 & 0 & 0 & 1 & 4 \\
\hline B.7 & Cultura corporativa & 1 & 1 & 1 & 1 & 1 & 1 & 6 \\
\hline B.8 & Processos gerenciais & 1 & 0 & 1 & 1 & 0 & 0 & 3 \\
\hline B.9 & Sistemas de informações & 1 & 1 & 1 & 1 & 0 & 1 & 5 \\
\hline C.1 & Clientes & 1 & 1 & 1 & 1 & 1 & 1 & 6 \\
\hline C.2 & Marketing & 0 & 1 & 1 & 1 & 1 & 1 & 5 \\
\hline C.3 & Contratos favoráveis & 0 & 1 & 1 & 0 & 0 & 1 & 3 \\
\hline C.4 & $\begin{array}{l}\text { Colaborações comerciais/ } \\
\text { Relacionamento com stakeholders }\end{array}$ & 1 & 1 & 1 & 1 & 1 & 1 & 6 \\
\hline C.5 & Acordos / Alianças & 1 & 1 & 1 & 1 & 0 & 0 & 4 \\
\hline C.6 & Canais de distribuição & 1 & 1 & 0 & 1 & 0 & 1 & 4 \\
\hline C.7 & Canais de atendimento/ Pós vendas & 1 & 1 & 1 & 1 & 0 & 1 & 5 \\
\hline \multicolumn{2}{|c|}{ TOTAL } & 17 & 19 & 21 & 19 & 9 & 14 & 99 \\
\hline
\end{tabular}

Fonte: Elaborado pelos autores. 
Das 6 empresas analisadas a que mais evidenciou o capital intelectual em seus relatórios foi o Banco Bradesco, citando 21 dos 25 tópicos analisados, seguido do Banco do Brasil e Itaú Unibanco, ambos com 19 citações.

Através da análise da Tabela 4 é possível verificar que os resultados se repetem aos obtidos na análise da tabela 3, em relação aos itens mais evidenciados do componente capital humano. Valorização do funcionário foi citado 21 vezes enquanto que o item Educação e Treinamento obtiveram 22 citações.

Pessoas são um ativo fundamental no processo de geração de valor do Bradesco. A Organização está atenta a questões como atração e retenção de talentos, qualidade de vida dos funcionários, desenvolvimento e crescimento dos profissionais e geração de emprego e renda. Tanto que estabelece como meta figurar nos principais rankings elaborados por consultorias conceituadas em relação ao tema clima organizacional. Em 2015, o Bradesco esteve presente nos principais rankings de público interno do País: as 130 Melhores Empresas para Trabalhar, da revista Época; As 150 Melhores Empresas para Você Trabalhar, da revista Você S/A; As Melhores na Gestão de Pessoas - Valor Carreira; e As Melhores Empresas para Começar a Carreira, também da Você S/A. (BANCO BRADESCO, 2015).
O que podemos inferir da analise dos relatórios quanto ao tópico do capital humano é que existe uma valorização por parte das organizações no que compete a este capital e, portanto, o desenvolvimento dos funcionários através de treinamentos é considerado um investimento e esta atrelado a geração de valor para as empresas.

Nossos indicadores de desempenho do capital humano são monitorados para medir a execução da estratégia de desenvolvimento desse capital. Além de indicadores financeiros, são observados dados como a quantidade de funcionários com, no mínimo, 34 horas de capacitação anuais; média de horas de treinamento presencial por funcionário; média de horas de treinamento à distância por funcionário; média de acessos diários ao Portal da Universidade Corporativa Banco do Brasil (UniBB); e percentual de gestores que realizaram a quantidade mínima de treinamentos gerenciais (BANCO DO BRASIL, 2015).

Com apenas 4 citações o item qualificação profissional/experiência foi o menos citados dos itens, sendo citado 3 vezes pelo Banco do Brasil e 1 vez pelo Banco Daycoval. 
TABELA 4: VOLUME ELEMENTOS DO CAPITAL INTELECTUAL NOS RELATÓRIOS DE SUSTENTABILIDADE.

\section{CAPITAL INTELECTUAL}

\section{AUTORES}

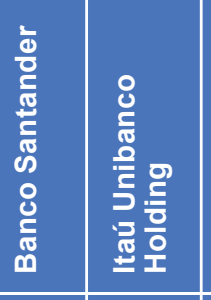

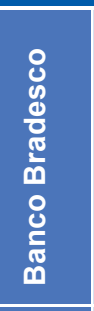

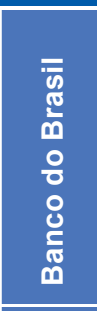

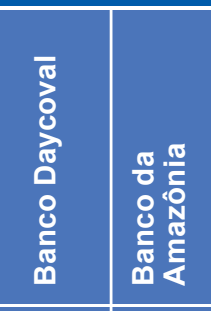

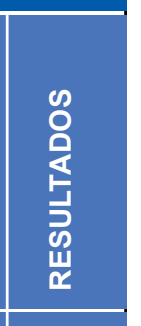

QUANTIDADE DE VEZES QUE CADA TÓPICO FOI MENCIONADO NO RELATÓRIO

\begin{tabular}{|c|c|c|c|c|c|c|c|c|}
\hline A.1 & Conhecimento e Competências & 2 & 2 & 3 & 3 & 0 & 0 & 10 \\
\hline A. 2 & Empreendedorismo e Inovação & 2 & 0 & 1 & 2 & 0 & 0 & 5 \\
\hline A. 3 & Liderança & 1 & 3 & 1 & 0 & 0 & 0 & 5 \\
\hline A. 4 & Qualificação vocacional/ Experiência & 0 & 0 & 0 & 3 & 1 & 0 & 4 \\
\hline A.5 & Valorização do funcionário & 6 & 3 & 5 & 3 & 1 & 3 & 21 \\
\hline A. 6 & Educação/ Treinamento & 2 & 4 & 6 & 6 & 2 & 2 & 22 \\
\hline A.7 & Colaboração & 5 & 0 & 0 & $\mathrm{o}$ & 1 & 0 & 6 \\
\hline A. 8 & Satisfação e motivação & 5 & 2 & 4 & 4 & 0 & 0 & 15 \\
\hline A. 9 & Estabilidade e baixa rotatividade & 0 & 1 & 2 & 2 & 0 & 2 & 7 \\
\hline
\end{tabular}

PROPRIEDADE INTELECTUAL

\begin{tabular}{|l|l|l|l|l|l|l|l|l|l|}
\hline & B.1 & Marcas e Patentes & 3 & 3 & 2 & 4 & 1 & 4 & $\mathbf{1 7}$ \\
\cline { 2 - 9 } & B.2 & Know how & 0 & 1 & 3 & 1 & 0 & 0 & $\mathbf{5}$ \\
\cline { 2 - 8 } & B.3 & Direitos autorais & 0 & 0 & 0 & 0 & 0 & 0 & $\mathbf{0}$ \\
\cline { 2 - 8 } & B.4 & $\begin{array}{l}\text { Produtividade processo pesquisa e } \\
\text { desenvolvimento }\end{array}$ & 0 & 0 & 2 & 0 & 0 & 2 & $\mathbf{4}$ \\
\hline
\end{tabular}

\section{ATIVOS DE INFRAESTRUTURA}

\begin{tabular}{|l|l|c|c|c|c|c|c|c|}
\hline B.5 & Adequação estrutural & 0 & 1 & 4 & 3 & 0 & 0 & 8 \\
\hline B.6 & Filosofia gerencial & 1 & 3 & 1 & 0 & 0 & 1 & $\mathbf{6}$ \\
\hline B.7 & Cultura corporativa & 4 & 3 & 6 & 1 & 1 & 1 & $\mathbf{1 6}$ \\
\hline B.8 & Processos gerenciais & 4 & 0 & 2 & 1 & 0 & 0 & $\mathbf{7}$ \\
\hline B.9 & Sistemas de informações & 6 & 6 & 10 & 8 & 0 & 3 & 33 \\
\hline C.1 & Clientes & 8 & 6 & 7 & 3 & 2 & 6 & $\mathbf{3 2}$ \\
\hline C.2 & Marketing & 0 & 3 & 1 & 1 & 1 & 2 & $\mathbf{8}$ \\
\hline C.3 & Contratos favoráveis & 0 & 1 & 1 & 0 & 0 & 1 & $\mathbf{3}$ \\
\hline C.4 & Colaborações comerciais/ & 14 & 6 & 8 & 10 & 3 & 8 & $\mathbf{4 9}$ \\
\hline C.5 & Acordos / Alianças & 3 & 5 & 1 & 2 & 0 & 0 & $\mathbf{1 1}$ \\
\hline C.6 & Canais de distribuição & 4 & 3 & 2 & 1 & 0 & 2 & $\mathbf{1 2}$ \\
\hline C.7 & Canais de atendimento/ Pós vendas & 2 & 2 & 6 & 3 & 0 & 3 & $\mathbf{1 6}$ \\
\hline TOTAL & 72 & 58 & $\mathbf{7 8}$ & $\mathbf{6 1}$ & 13 & $\mathbf{4 0}$ & 322 \\
\hline
\end{tabular}

Fonte: Elaborado pelos autores. 
No que tange a Capital estrutural os tópicos mais citados foram o da Cultura corporativa e de Sistemas de Informação, obtendo 23 e 38 citações respectivamente.

No Relatório de sustentabilidade do Bradesco o item Sistemas de Informação, foi citado 10 vezes, e embora seja um tópico do capital estrutural sua evidenciação esteve em vários momentos atrelada ao capital de cliente devido ao uso massivo da tecnologia e inovação no sentido de facilitar o dia-a-dia do cliente, e por consequência fideliza-lo. No ano de 2015 o investimento do Bradesco em infraestrutura, tecnologia da informação e telecomunicações foi de R $\$$ 5,720 bilhões. Entre os investimentos foi citado em seu relatório aquisição de um novo mainframe que ampliou para $40 \%$ a capacidade do computador central do Bradesco Seguros.

\begin{abstract}
Os investimentos em TI reduzem custos, melhoram os controles e a segurança da informação, liberam os funcionários para que atuem com os clientes e em projetos estratégicos e minimizam o impacto ambiental das atividades do Banco (BANCO DO BRASIL, 2015).
\end{abstract}

No relatório do Itaú Unibanco extraímos que o banco investe em tecnologia por acreditar que assim pode melhorar o mundo de seus colaboradores e clientes, neste sentido prioriza os esforços no desenvolvimento de plataformas e serviços que utilizam o melhor da tecnologia, com o objetivo de simplificar e facilitar a vida de todos que se relacionam com o banco.

Embora muito citado o item Sistemas de informação diferente da teoria foi mais observado com as ações direcionadas ao público externo do que ao interno, embora tenha ações para este último também. Isso se deve a observação pelas organizações na identificação de um público cada vez mais conectado com o uso da tecnologia e buscando mais praticidade em seu dia a dia.

Clientes e Relacionamento com Stakeholders foram os tópicos mais abordados no que se refere a evidenciação do Capital Relacional, e também de todos os tópicos de Capital Intelectual, corroborando com o que foi abordado na pesquisa de Sousa, et al (2008). O item clientes foi abordado 32 vezes em nosso estudo, sendo 8 vezes pelo Banco Santander, 7 pelo Bradesco e 6 pelo Itaú Unibanco.

O Banco Santander conta com uma carteira de aproximadamente 121 milhões de clientes, e de acordo com o extraído de seu relatório uma de suas prioridades é impulsionar relações com os clientes com foco na sua fidelização, pois um cliente satisfeito será mais leal e, portanto, será um cliente que irá utilizar o Banco por mais tempo.

O Capital Relacional não se limita apenas aos clientes, o tópico relacionamento com Stakeholders por exemplo obteve 49 citações nos relatórios, e foi o item mais abordado do CI. Os Stakeholders contemplam os funcionários, os clientes, acionistas, fornecedores, governos e sociedade como um todo.

Identificamos em quase todos os relatórios uma preocupação e responsabilidade na contratação de fornecedores.

\begin{abstract}
Em setembro de 2015, com o início da implantação do novo sistema para homologação de fornecedores, todas as empresas $(100 \%)$ passaram a ser avaliadas sob aspectos socioambientais, cadastrais, comerciais e econômico-financeiros. Caso a empresa não atinja a nota mínima de $50 \%$, são elaborados planos de oportunidades de melhoria, com o planejamento de ações de adequação e cumprimento da legislação (BANCO BRADESCO, 2015).
\end{abstract}

Para o Banco do Brasil as relações com funcionários, fornecedores, parceiros, clientes, credores, acionistas, concorrentes, comunidade, governo e entidades ligadas ao meio ambiente são pautadas pela ética, pelo respeito e pela transparência.

O Itaú Unibanco possui processos de engajamento com Stakeholders que estão baseados em diretrizes internas, que definem a metodologia para conquistar o engajamento de seus Stakeholders com relação à estratégia de sustentabilidade. Tal metodologia começa com a priorização dos públicos (colaboradores, clientes, acionistas, sociedade ficação de questões fundamentais, selecionadas com base nos impactos social, ambiental e econômico para a organização e os Stakeholders envolvidos.

\section{CONCLUSÃO}

O objetivo desta pesquisa foi analisar a evidenciação do capital intelectual nos relatórios de sustentabilidade e foi possível concluir que, embora não haja citação direta do capital intelectual, bem como suas divisões em capital humano, estrutural e relacional, os relatórios de sustentabilidade das empresas analisadas evidenciaram os elementos que constituem o Capital Intelectual.

Em relação ao capital humano, todas as empresas evidenciaram os aspectos: valorização dos funcioná- 
rios; educação e treinamentos; marcas e patentes; cultura corporativa; clientes e colaborações comerciais/ relacionamento com stakeholders.

Com relação ao volume de evidenciações, os itens mais evidenciados foram "Colaborações comerciais/ Relacionamento com stakeholders" e "Clientes" no capital relacional, "Sistemas de informações" no capital estrutural e "Valorização do funcionário" e "Educação/ Treinamento" no capital humano.

Por fim, este trabalho contribuir com a teoria acerca do tema capital intelectual evidenciando a sua relação com a sustentabilidade e que ambos estão muito relacionados pois refletem compromisso, transparência, valorização da marca, e consequentemente geração de valor para as organizações.
Do ponto de vista gerencial esta pesquisa permite com que os gestores de instituições financeiras melhorem seus relatórios de sustentabilidade e planejem melhor suas ações relacionadas à gestão do capital intelectual.

Quantos as limitações da pesquisa, por ser documental, não se pode afirmar que os dados encontrados nos relatórios são realmente aplicados na prática e que a interpretação destes depende do autor.

Como sugestão para trabalhos futuros, fica a comparação entre dois ou mais anos, a fim de se analisar a variação do nível de evidenciação, bem como a mensuração das informações referentes ao Capital Intelectual.

\section{REFERÊNCIAS}

ANTUNES. M. T. P. O Capital Intelectual segundo o entendimento dos gestores de empresas brasileiras. Revista Brasileira de Gestão de Negócios, v. 7 n. 19, p. 9-20 2005.

AVILA, L. V., MADRUGA, R. da R. G, BEURON, T. A. Planejamento de Sustentabilidade: O Caso das Instituições Deferias de Ensino. Revista de Gestão Ambiental e Sustentabilidade - GEAS, v. 5 n. 1, p. 96 98. 2016.

BANCO AMAZONIA. Relatório de Sustentabilidade 2015. Disponível em: $<$ http://www.bancoamazonia. com.br/index.php/component/jdownloads/viewcategory/128-relatorio-2015?Itemid=666> Acesso em 15 out. 2016.

BANCO BRADESCO. Relatório Integrado 2015. Disponível em: <https:/www.bradescori.com.br/site/ conteudo/informacoes-financeiras/relatorios-sustentabilidade.aspx?secaoId=723> Acesso em 15 out. 2016.

BANCO DAYCOVAL. Relatório de Sustentabilidade 2015. Disponível em: $<<$ https://www.daycoval.com. br/Content/Documentos/RelatorioSustentabilidade2015.pdf $>$ Acesso em 15 out. 2016.

BANCO DO BRASIL. Relatório Anual 2015. < www.bb.com.br/docs/pub/siteEsp/uds/dwn/BBRA15.pdf> Acesso em 15/10/2016.

BANCO SANTANDER. Relatório de Sustentabilidade 2015. Disponível em: $<$ https://sustentabilidade. santander.com.br/pt/governanca/paginas/relatorios.aspx> Acesso em 15 out. 2016.

BARAKAT, S. R. et al. Associação entre desempenho econômico e índice de Sustentabilidade Empresarial da Bolsa de Valores de São Paulo. Gestão \& Regionalidade Contabilidade, v.32, n.95, 127-142, 2016.

BERTOLLA, F. L. et al. Capital Intelectual como recurso na retenção de cliente. Revista Pensamento Contemporâneo em Administração. v.9, n. 3, p. 155-168, 2015.

CARLOS FILHO, F. A. et al. Importância e Contribuição do Ativo Intangível: Percepção dos Empreendedores de Micro e Pequenas Empresas Sobre o Capital Intelectual. Organizações em contexto. v.10, n. 20, p.1-27, 2014. 
CARVALHO. A. C. M.; SOUZA, L P. Ativos intangíveis ou capital intelectual: discussões das contradições na literatura e propostas para sua avaliação. Revista Administração e Dialogo, v. 13, n. 3, p. 69-90, 2011.

CONSELHO BRASILEIRO PARA O DESENVOLVIMENTO SUSTENTÁVEL (CEBDS). GT de empresas pioneiras em relatórios de sustentabilidade. Disponível em: $<$ http://cebds.org/publicacoes/gt-de-empresaspioneiras-em-relatorios-de-sustentabilidade/\#.V7EhATb6vIU> Acesso em 10/ ago. 2016.

CORREA, R. et al. Evolução dos Níveis de Aplicação de Relatórios de Sustentabilidade (GRI) de Empresas do ISE/Bovespa. Sociedade, Contabilidade e Gestão, Rio de Janeiro, v. 7, n. 2, p. 24-40, 2012.

EDVINSSON, L; MALONE, M.S. Capital Intelectual. São Paulo: Makron Books, 1998.

ELKINGTON, J. Sustentabilidade, canibais com garfo e faca. São Paulo: M. Books do Brasil Ltda., 2012.

GIL, A. C. Como elaborar projetos de pesquisa. 4.Ed. São Paulo. Editora Atlas, 2002.

Global RePorting InItiative (GRI). Pontos de Partida. Disponível em: <https://www. globalreporting.org/resourcelibrary/Portuquese-Starting-Points-2-G3.1.pdf $>$ Acesso em 10/08/2016.

INSTITUTO FILANTROPIA. Triple Bottom Line: O Tripé da Sustentabilidade. Disponível em: <http:// www.institutofilantropia.org.br/component $/ \mathrm{k} 2 /$ item/1607-triple_bottom_line_o_tripe_da_sustentabilidade> Acesso em 01 out. 2016.

ITAU UNIBANCO. Relatório Anual 2015. Disponível em: <https://www.itau.com.br/_arquivosestaticos/RI/ pdf/pt/Itau_RAC_2015_port.pdf.> Acesso em 15 out. 2016.

KNEIPP, J. M. at al. Características determinantes no nível de divulgação de informação em relatórios de sustentabilidade de empresas brasileiras. RACE - Unoesc, v. 12, n. 2, p. 295-338, 2013.

MARQUES, R. O.; GOMES, A. V. Analise de indicadores de capital intelectual: Estudo de caso em uma empresa atacadista. RAD, v.13, n.13, p. 69-90, 2011.

MOREIRA, F. G.; VIOLIN, F. L; DA SILVA, L. C. Capital Intelectual como vantagem competitiva: um estudo bibliográfico. Revista de Carreiras e Pessoas, v. 4, n. 3, p. 296-311, 2014.

PACHECO, V. Mensuração e divulgação de Capital Intelectual nas Demonstrações Contábeis: teoria e empiria, 2005. Tese (Doutorado de Engenharia de Produção). Universidade Federal de Santa Catarina, Florianópolis, 2005.

REINA, D.; ENSSLIN, S. R.; VICENTE, E. F. R. Capital intelectual: analise comparativa em empresas de governança. Pretexto, v.10, n.1, p.9-27, 2009.

REZENDE, J. F. de C.; AVILA, M., MAIA, R. S, Geração e gestão do valor por meio de métricas baseadas nas perspectivas do capital intelectual. Revista de Administração, v. 47, n. 1, p. 51-67, 2012.

SOUZA, R. B. DE; LOPES, P. C. Indicadores de Sustentabilidade em Simulações de Negócios: Uma Proposição no Contexto do Jogo de Empresas SEE. Revista Contemporânea de Economia e Gestão, v. 8, n. 2, p. 7-18, 2010.

SOUSA, B.J., et al. Um Estudo sobre a Evidenciação de Capital Intelectual nos Relatórios da Administração das 15 Maiores Distribuidoras de Energia Elétrica do Brasil nos anos de 2006 e 2007. Revista UnB Contábil, v. 11, n. 1-2, p.187-207, 2008. 
STEWART, T.A. Capital Intelectual: a nova vantagem competitiva das empresas. 10. Ed. Rio de Janeiro: Campus, 1998.

VAZ, C. R. et al. Capital intelectual: classificação, formas de mensuração e questionamento sobre usos futuros. Revista de Gestão e Tecnologia, Florianópolis, v. 5, n.2, p.73-92, 2015.

ZANOL, C.T., ECKERT, A., MECCA, M. S., BIASIO, R. A evidenciação do capital intelectual nos relatórios de sustentabilidade das empresas de energia elétrica listadas na BMF \& Bovespa. MOSTRA DE INICIAÇÃO CIENTIFICA, 15. Programa de Pós-Graduação em Administração - UCS. 